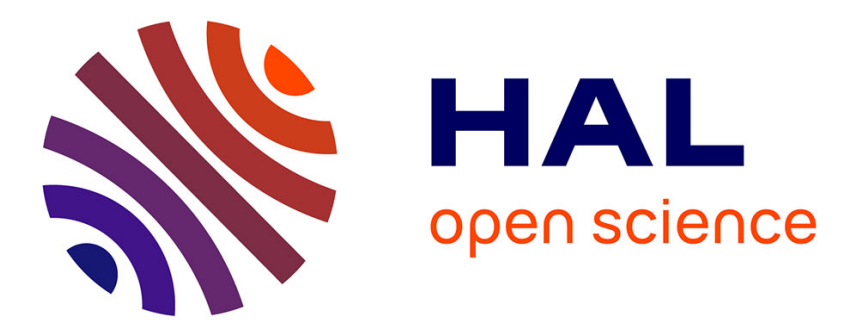

\title{
Neutron diffraction investigation and structural model for liquid gallium from room temperature up to $1303 \mathrm{~K}$
}

A. Bizid, A. Defrain, R. Bellissent, G. Tourand

\section{To cite this version:}

A. Bizid, A. Defrain, R. Bellissent, G. Tourand. Neutron diffraction investigation and structural model for liquid gallium from room temperature up to $1303 \mathrm{~K}$. Journal de Physique, 1978, 39 (5), pp.554-560. 10.1051/jphys:01978003905055400 . jpa-00208787

\section{HAL Id: jpa-00208787 https://hal.science/jpa-00208787}

Submitted on 1 Jan 1978

HAL is a multi-disciplinary open access archive for the deposit and dissemination of scientific research documents, whether they are published or not. The documents may come from teaching and research institutions in France or abroad, or from public or private research centers.
L'archive ouverte pluridisciplinaire HAL, est destinée au dépôt et à la diffusion de documents scientifiques de niveau recherche, publiés ou non, émanant des établissements d'enseignement et de recherche français ou étrangers, des laboratoires publics ou privés. 


\title{
NEUTRON DIFFRACTION INVESTIGATION AND STRUCTURAL MODEL FOR LIQUID GALLIUM FROM ROOM TEMPERATURE UP TO $1303 \mathrm{~K}$
}

\author{
A. BIZID $\left({ }^{*}\right)(* *)$ and A. DEFRAIN $(*)$, R. BELLISSENT and G. TOURAND \\ DPh-G/PSRM, C.E.N. Saclay, Boîte Postale no 2, 91190 Gif-sur-Yvette, France
}

(Reçu le 27 octobre 1977, révisé le 4 janvier 1978, accepté le 11 janvier 1978)

\begin{abstract}
Résumé. - Des mesures de diffusion de neutrons par le gallium liquide ont été réalisées sur le spectromètre $\mathrm{H} 10$ du réacteur EL3 à Saclay.

Les facteurs de structure et les fonctions de corrélation de paire obtenus sont comparés à divers résultats de la littérature.

Un modèle quasi cristallin rattaché à la forme monoclinique $\beta$ du gallium est proposé pour expliquer le comportement du facteur de structure du gallium à l'état liquide et son évolution en fonction de la température.
\end{abstract}

Abstract. - Neutron scattering measurements on liquid gallium have been carried out at 293, 838 and $1303 \mathrm{~K}$ on the $\mathrm{H} 10$ spectrometer of the EL3 reactor at Saclay.

The obtained structure factors and pair correlation functions are compared to various published data.

A quasi-crystalline model related to the $\beta$ monoclinic form of gallium is proposed in order to explain the shape of the structure factor of liquid gallium and its behaviour versus temperature.

1. Introduction. - The particular properties of gallium at low temperatures, namely the polymorphism, the low melting point $\left(T_{\mathrm{M}} \simeq 303 \mathrm{~K}\right)$ a high boiling point at normal pressure $\left(T_{\mathrm{B}} \simeq 2510 \mathrm{~K}\right)$ and a very large temperature range for the supercooled state (from 150 to $303 \mathrm{~K}$ ) have resulted in several studies of the liquid state [1-11].

If one examines these studies large discrepancies appear. We have therefore undertaken a structural study of liquid gallium up to $1303 \mathrm{~K}$ by use of thermal neutron scattering. We describe briefly the experimental device and the procedure used to obtain the structure factor of liquid gallium at various temperatures from the scattered intensity. We then give the corresponding radial distribution functions, obtained by a Fourier transform, from which the distances and coordination numbers are calculated. Then, after a comparison between various simulated structure factors and those measured, we propose a quasi-crystalline model for liquid gallium which is consistent with the variations of local order versus temperature.

(*) Groupe de Recherche $\mathrm{n}^{\circ} 4$ du CNRS, Physique des Liquides et Electrochimie, associé à l'Université Paris-VI, 4, place Jussieu, Tour 22, 75230 Paris Cedex 05, France.

${ }^{* *}$ ) Present address : Laboratoire de Sciences Physiques, Ecole Normale Supérieure, 43, rue de la Liberté, Le Bardo, Tunis, Tunisie.
2. Device and measurements. - Our measurements were carried on the H10 spectrometer of the EL3 reactor at Saclay. This device has been previously described $[12,13,14]$ with its ancillary equipment and we shall only recall its main characteristics.

A monochromatic neutron beam with a $1.133 \AA$ neutron wavelength provides a flux of about $2 \times 10^{6}$ neutrons $\mathrm{cm}^{-2} \mathrm{~s}^{-1}$. We cover the range of 0.1 to $9.4 \AA^{-1}$ wavevectors in steps of about $0.02 \AA^{-1}$. The statistical error is about $2 \%$.

A high purity gallium sample $(99.9999 \%)$ is placed in a vitreous silica container, the inner and outer diameters of which are respectively 10 and $12 \pm 0.5 \mathrm{~mm}$. Figure 1 shows the experimental environment of the sample. Vitreous silica was chosen as sample holder because of its neutronic characteristics (amorphous state and a weak absorption for thermal neutrons) as well as for other experimental advantages (chemical inertia with respect to liquid gallium in the temperature range considered and transparency to pyrometer wavelengths).

The sample was previously outgassed at the experimental temperature under a dynamical vacuum, then the silica tubes were sealed at room temperature under a $10^{-6}$ torr vacuum.

The sample temperature was obtained from a high frequency induction device. The inductors used have 


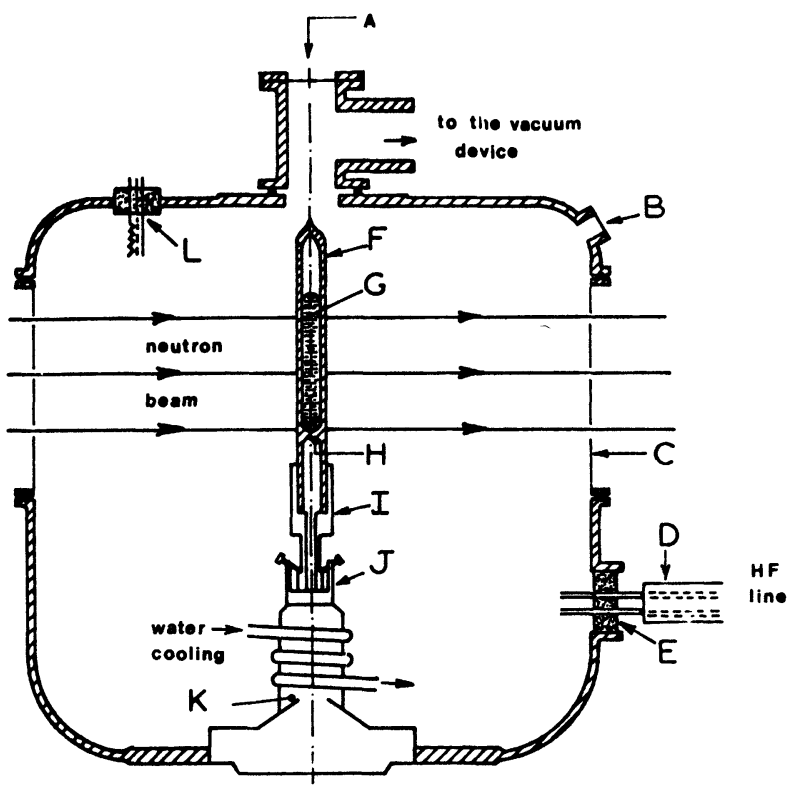

FIG. 1. - Sample disposition inside the vacuum vessel. A Viewing window. B Window for pyrometric measurements. C Aluminium window for the neutron beam. D H.F. Line. E H.F. insulating feedthrought. F Vitreous silica container. G Sample. H The W/W-Re thermocouple. I Lava holder. J Fixation ring. K Centring cylinder. L Vacuum gauge.

been designed such that they never intercept the incident and scattered beams.

The temperature measurements were performed by using two optical pyrometers. The first one was used above $900 \mathrm{~K}$ and the second one in the temperature range between 500 and $1000 \mathrm{~K}$ : Their utilization necessitated a prior measurement of the gallium emissivity $\varepsilon$ by comparison of the obtained set-up temperature to those indicated by a thermocouple. Our results $(\varepsilon \simeq 0.12)$ were in good agreement with previous data [15].

The H.F. generator $(17 \mathrm{~kW}$ power) uses an oscillating tube of $0.7 \mathrm{MHz}$ frequency. The sample temperature is kept constant by an electronic regulation with proportional, integral and derivative action on the generator voltage. The regulation is derived from a chromel-Alumel thermocouple located in the imme- diate neighbourhood of the liquid sample or by the optical pyrometer. The maximum fluctuation of this regulation was about half a degree.

Several measurements of temperature on liquid samples, showed that the radial and longitudinal gradients are very small and never exceed $\pm 2 \mathrm{~K}$ in the explored temperature range.

3. Experimental results and corrections. - In order to obtain the structure factor of liquid gallium, we have first determined two diffusion spectra. The first $I_{0}$ represents the scattered intensity coming from the empty container and the second $I_{1}$ is the scattered intensity due to the gallium sample and its container. In order to obtain the theoretical intensity which should be scattered by the sample alone, we must apply several corrections.

3.1 ABSORPTION CORRECTION. - We have used a method due to Paalman and Pings [16]. We have first determined the linear absorption coefficient for liquid gallium. The value found differs slightly from those calculated from the compilation of G. E. Bacon [17] but is in better agreement with that of B.N.L. 325 [18] which was confirmed by Ascarelli [4].

Table I shows the three values of this coefficient.

TABLE I

Linear attenuation coefficient of solid $\mathrm{Ga} \alpha$ at room temperature

Our measurements BNL 325 Bacon

\begin{tabular}{|c|c|c|}
\hline$\lambda(\AA)$ & 1.133 & 1.133 \\
\hline$\mu\left(\mathrm{cm}^{-1}\right)$ & $0.392 \pm 0.005$ & 0.43 \\
\hline
\end{tabular}

If we then assume a linear behaviour of this coefficient versus bulk density, we obtain a set of values for the three experimental temperatures (Table II).

TABLE II

Density and attenuation coefficient of gallium versus temperature

\begin{tabular}{|c|c|c|c|c|c|}
\hline \multirow{3}{*}{ Sample state } & \multirow[b]{2}{*}{$\begin{array}{l}\text { Temperature } \\
\text { (K) }\end{array}$} & \multicolumn{3}{|c|}{ Bulk density } & \multirow{2}{*}{$\begin{array}{c}\text { Linear } \\
\text { attenuation } \\
\text { coefficient } \\
\mu\left(\mathrm{cm}^{-1}\right)\end{array}$} \\
\hline & & $d\left(\mathrm{~g} \cdot \mathrm{cm}^{-3}\right)$ & $\rho_{0}\left(\right.$ at. $\left.\AA^{-3}\right)$ & Reference & \\
\hline & - & - & - & - & - \\
\hline Solid Ga $\alpha$ & 293 & 5.904 & 0.0510 & [19] & 0.392 \\
\hline $\begin{array}{l}\text { Supercooled liquid gal- } \\
\text { lium }\end{array}$ & 293 & 6.112 & 0.0528 & [20] & 0.406 \\
\hline Stable liquid gallium & 838 & 5.743 & 0.0496 & [21] & 0.381 \\
\hline Stable liquid gallium & 1303 & 5.482 & 0.0474 & [22] & 0.364 \\
\hline
\end{tabular}


The global intensity $I_{\mathrm{S}}$ scattered by the sample alone may then be written

$$
I_{\mathrm{S}}=\alpha_{1}\left[I_{1}-\alpha_{0} I_{0}\right]
$$

where $\alpha_{0}$ and $\alpha_{1}$ represent various absorption factors which depend on the geometry and linear absorption coefficients of the container and the sample.

3.2 MUlTIPLE SCATTERING. - We have computed the amount of multiple scattering following the method of Blech and Averbach [23]. This correction, to first order is less than $0.5 \%$, moreover it is constant with the wave vector modulus $q=4 \pi \sin \theta / \lambda$. This point is confirmed by the previous experimental measurements of Antonini and Corchia [24] on liquid gallium at 323 and $423 \mathrm{~K}$ in the range $0 \leqslant q \leqslant 12 \AA^{-1}$.

3.3 INELASTICITY CORRECTION. - In order to take into account inelasticity effects, we have applied a Placzek [25] type correction, due to Yarnell et al. [26], to the scattered intensity. It enables us to take into account the real efficiency of the $\mathrm{BF}_{3}$ detector.

We then obtain the structure factor by normalization versus coherent scattering for large $q$ following the relation

$$
S(q)=\frac{I_{\mathrm{coh}}(q)}{I_{\mathrm{coh}}(\infty)}=\frac{I(q)-X}{I(\infty)-X}
$$

where $X$ is the sum of the incoherent and the multiple scattered intensities, which are assumed to be isotropic.

We determine $X$ by the relation

$$
S(0)=\frac{I(0)-X}{I(\infty)-X}=k_{\mathrm{B}} T \rho_{0} \beta_{T}
$$

which relates the limit value of the structure factor $S(0)$ to the isothermal compressibility $\beta_{T}, k_{\mathrm{B}}$ is the Boltzmann constant.

3.4 StruCture Factors. - The obtained structure factors $S(q)$ are represented in figure 2. They respectively correspond to 293,838 and $1303 \mathrm{~K}$. The main features of these structure factors consist of a drastic evolution of the first peak with temperature. Its height decreases from 2.51 to 1.87 and 1.67 when the temperature increases.

A well defined shoulder appears on the high angle side of the main peak. This shoulder is still present at $838 \mathrm{~K}$ and vanishes below $1303 \mathrm{~K}$. Another shoulder may be present on the right side of the second peak but the statistical error (a few percent) does not allow us to say whether or not it is significant.

Moreover, the amplitudes of the other maxima of $S(q)$ decreases when the temperature increases and at $1303 \mathrm{~K}$ it is very difficult to see oscillations of $S(q)$

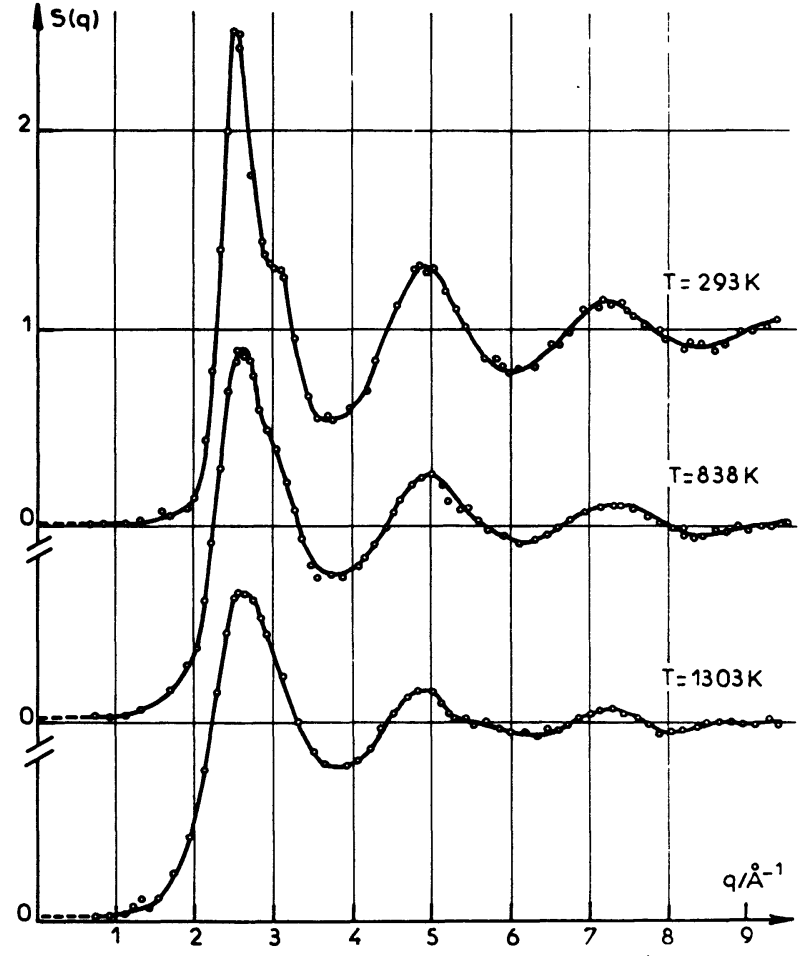

FIG. 2. - Structure factors obtained by neutron diffraction from liquid gallium at 293, 838 and $1303 \mathrm{~K}$.

for $q>8 \AA^{-1}$. Table III shows some features of our structure factors and compares them with various published ones [27]. The examination of this table shows fairly good agreement with the positions of the peaks but some discrepancies in the amplitudes of the peaks.

3.5 RAdial Distribution FUNCTIONS. - By a Fourier transform, we have computed the corresponding radial distribution functions which are shown in the figure 3. In order to shed light on the cut-off effect we have used three different truncations of the structure factor $\left(9.4,7.8\right.$ and $\left.6.7 \AA^{-1}\right)$.

We have calculated the number $N_{1}$ of nearest neighbours under the first peak of the function

$$
D(r)=4 \pi r^{2} \rho_{0} g(r)
$$

and the following table $\mathrm{V}$ gives a comparison with some previous results obtained by similar methods. This comparison shows that our nearest neighbour number exhibits a weaker dependence on temperature than those calculated by other authors. However, it decreases when the temperature increases.

On the other hand this number is greater than those $\left(N_{1}=7\right)$ of the stable $\mathrm{Ga} \alpha$ solid form. As a conclusion, liquid gallium behaves as a non-compact system, so that it seemed interesting to try to explain its local order by use of a quasi-crystalline model. 
TABLE III

Positions and heights of the peaks of our measured structure factors and some previously published results

First peak shoulder Second peak Third peak

\begin{tabular}{|c|c|c|c|c|c|c|c|c|}
\hline References & $T(\mathrm{~K})$ & $q_{1}(\AA)$ & $S\left(q_{1}\right)$ & $q_{1}^{\prime}\left(\AA^{-1}\right)$ & $q_{2}$ & $S\left(q_{2}\right)$ & $q_{3}$ & $\underline{S\left(q_{3}\right)}$ \\
\hline \multirow{3}{*}{$\begin{array}{l}\text { This work neutrons, } \\
\lambda=1.133 \AA\end{array}$} & 293 & 2.55 & 2.51 & 3.1 & 4.90 & 1.32 & 7.22 & 1.12 \\
\hline & 838 & 2.58 & 1.87 & 3.1 & 4.98 & 1.24 & 7.30 & 1.10 \\
\hline & 1303 & 2.61 & 1.67 & - & 4.92 & 1.165 & 7.26 & 1.06 \\
\hline A. Bizid et al., X-Rays [5], & 203 & 2.51 & 2.74 & 3.12 & 4.87 & 1.41 & 7.20 & 1.17 \\
\hline 1977 & 323 & 2.52 & 2.43 & 3.10 & 4.88 & 1.33 & 7.25 & 1.12 \\
\hline \multirow[t]{3}{*}{ Y.Waseda, X-Rays [6], 1975} & 323 & 2.52 & 2.30 & 3.1 & 4.9 & 1.30 & 7.3 & 1.11 \\
\hline & 823 & 2.53 & 1.95 & 3.05 & 4.9 & 1.20 & 7.4 & 18 \\
\hline & 1273 & 2.56 & 1.69 & - & 5.0 & 1.160 & 7.6 & 1.04 \\
\hline $\begin{array}{l}\text { A. H. Narten, X-Rays + } \\
\text { Neutrons [7], } 1972\end{array}$ & 293 & 2.52 & 2.50 & 3.12 & 4.90 & 1.36 & 7.20 & 1.1 \\
\hline \multirow{3}{*}{$\begin{array}{l}\text { A. S. Lashko and Yu. G. } \\
\text { Poltavtsev, X-Rays [8], } \\
1968\end{array}$} & 292 & 2.5 & 2.09 & $2.8-3.1$ & 4.7 & - & 6.9 & - \\
\hline & 823 & - & 1.88 & $2.8-3.2$ & 4.6 & - & 7.4 & \\
\hline & 1123 & - & 1.60 & - & - & - & - & - \\
\hline \multirow{4}{*}{$\begin{array}{l}\text { M. S. Zei and B. Steffen, } \\
\text { X-Rays [11], } 1977\end{array}$} & 286 & 2.5 & 2.46 & 3.0 & 4.9 & 1.34 & 7.3 & 1.14 \\
\hline & 323 & - & 2.35 & - & 4.9 & 1.32 & 7.3 & 1. \\
\hline & 373 & 2.6 & 2.24 & - & 5.0 & 1.30 & 7.3 & 1.12 \\
\hline & 523 & 2.6 & 2.06 & - & 4.9 & 1.25 & 7.3 & 1.10 \\
\hline \multirow{3}{*}{$\begin{array}{l}\text { C. N. J. Wagner, X-Rays [9], } \\
1976\end{array}$} & 298 & 2.53 & $\sim 2.35$ & 3.1 & 4.8 & - & 7.2 & - \\
\hline & 773 & - & 1.82 & - & - & - & - & \\
\hline & 1073 & - & 1.71 & - & - & - & - & \\
\hline
\end{tabular}

TABLE IV

Positions and heights of the peaks of the radial distribution function $g(r)$ and comparison with previously published results

First peak Second peak Third peak

\begin{tabular}{|c|c|c|c|c|c|c|c|}
\hline Reference & $T(\mathrm{~K})$ & $r_{1}(\AA)$ & $g\left(r_{1}\right)$ & $r_{2}(\AA)$ & $g\left(r_{2}\right)$ & $r_{3}(\AA)$ & $g\left(r_{3}\right)$ \\
\hline \multirow{3}{*}{$\begin{array}{l}\text { Our measurements neutrons, } \\
\lambda=1.133 \AA\end{array}$} & 293 & 2.81 & 2.96 & 5.50 & 1.20 & 8.24 & 1.09 \\
\hline & 838 & 2.82 & 2.42 & 5.31 & 1.12 & 8.15 & 1.03 \\
\hline & 1303 & 2.85 & 2.08 & 4.55 & 1.02 & 5.35 & 1.13 \\
\hline \multirow{2}{*}{ A. Bizid et al., X-Rays [5], 1977} & 203 & 2.80 & 2.95 & 5.50 & 1.20 & 8.20 & 1.12 \\
\hline & 323 & 2.78 & 3.39 & 5.48 & 1.16 & 8.25 & 1.08 \\
\hline $\begin{array}{l}\text { A. H. Narten, X-Rays + neu- } \\
\text { trons [7], } 1972\end{array}$ & 293 & 2.80 & 3.29 & 5.5 & 1.19 & 8.2 & 1.10 \\
\hline \multirow[t]{3}{*}{ Y. Waseda, X-Rays [6], 1975} & 323 & 2.82 & 2.62 & 5.50 & 1.16 & 8.15 & 1.07 \\
\hline & 823 & 2.80 & 2.25 & 5.50 & 1.13 & 8.20 & 1.04 \\
\hline & 1273 & 2.78 & 1.92 & 5.45 & 1.10 & 8.2 & 1.02 \\
\hline \multirow{3}{*}{$\begin{array}{l}\text { K. Suzuki et al., pulsed neutrons } \\
\text { [10], } 1975\end{array}$} & 313 & 2.85 & 2.98 & 5.5 & - & 8.3 & - \\
\hline & 728 & 2.80 & 2.23 & 5.4 & - & 8.3 & - \\
\hline & 1193 & - & 1.91 & 5.5 & - & - & - \\
\hline
\end{tabular}




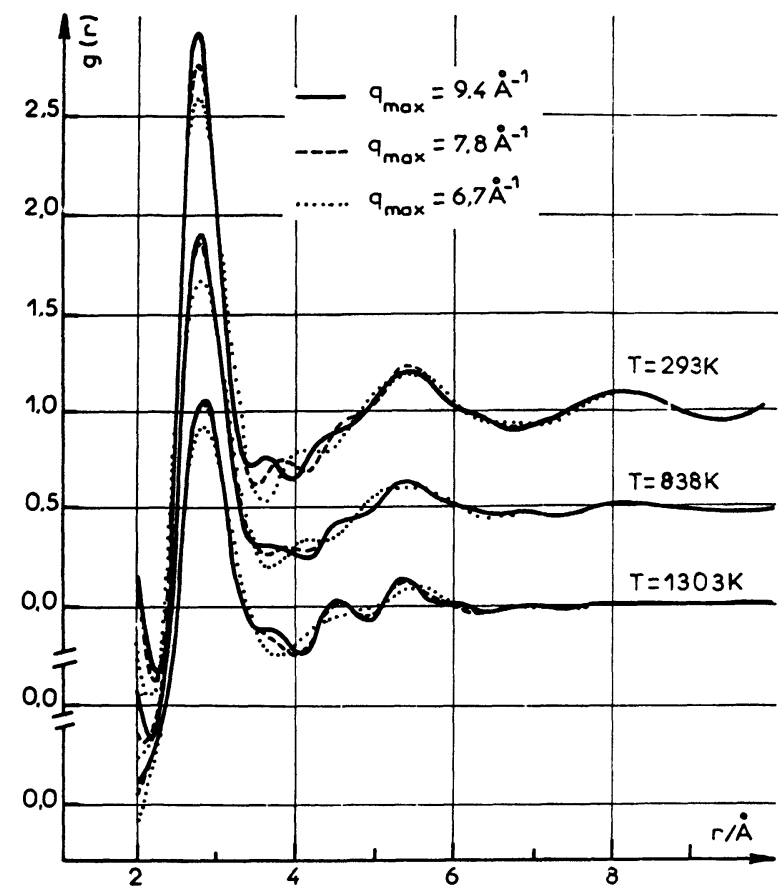

FIG. 3. - Pair correlation functions for gallium at 293, 838 and $1303 \mathrm{~K}$, for different cut-off $\left(q_{\max }\right)$ values of the structure factors.

\section{TABLE V}

Nearest neighbour numbers of liquid gallium versus temperature and comparison with some previously published results.

\begin{tabular}{|c|c|c|}
\hline Reference & $T(\mathrm{~K})$ & $N_{1}$ (atoms) \\
\hline \multirow[t]{3}{*}{ This work neutrons } & 293 & 10.2 \\
\hline & 838 & 9.2 \\
\hline & 1303 & 8.4 \\
\hline izid et al. & 203 & 10.1 \\
\hline X-Rays [5] & 323 & 9.9 \\
\hline
\end{tabular}

A. H. Narten

X-Rays + neutrons 1972 [7] 293

P. Ascarelli 323 neutrons [4] 1966

Ya. I. Dutchak et al. (1962) [1] 293

A. Bizid et al. (1974)

$\mathrm{X}$-Rays [2]

S. E. Rodriguez and C. J. Pings (1965)
4. Quasi-crystalline model. - 4.1. Simulation METHOD. - The method used in order to obtain a simulated structure factor has been described in two previous papers $[28,29]$. The first step is the computation of every interatomic distance within a sphere of radius $L$ (where $L$ may be considered as a correlation length) in a trial structural model. Then, by assuming a gaussian distribution of the distances around the mean, we obtain a pair correlation function, which will be normalized regarding the mean density and the number of atoms corresponding to every set of distances. The structure factor may be calculated by a Fourier transform.

4.2 TRIal mOdels. - The various crystalline forms of gallium have been used as starting points for the computation described here. The four obtained structure factors are plotted versus the wave-vector modulus $q$ in figure 4. As shown in this figure only the $\beta$ form exhibits a fair agreement with positions of the peaks of the experimental structure factor at room temperature. This agreement between the computed $S(q)$ and the experimental one is necessary because it depends on the distribution of the pair distances in the chosen model. It may be possible to adjust the height of the various peaks of the structure factor by modifying the half-height width of the gaussian distributions. However any fit becomes impossible if the abscissa are different. We have therefore taken the $\beta$ crystalline form of $\mathrm{Ga}$ as a starting point of the model.

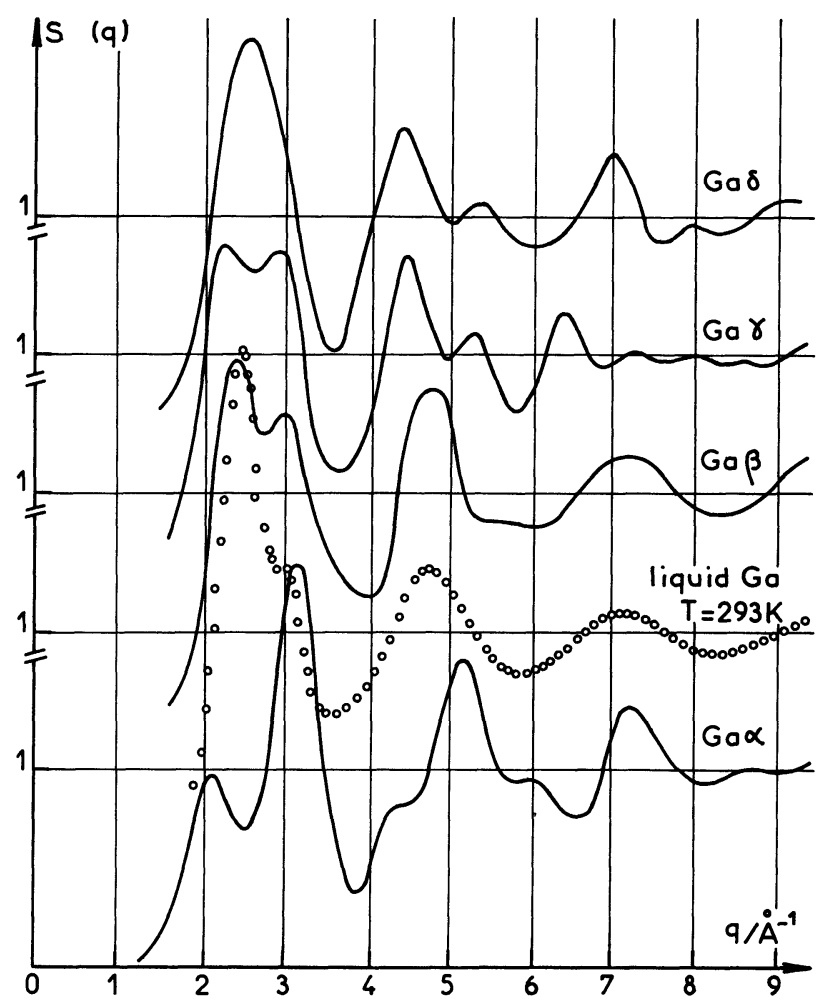

FIG. 4. - Comparison between various simulated structure factors and the observed structure factor at $293 \mathrm{~K}$. 
4.3 COMPARISON BETWEEN SIMULATED AND EXPERIMENTAL STRUCTURE FACTORS. - In figure 5, we present a comparison between the calculated and experimental structure factors, corresponding respectively to the temperatures 293,838 and $1303 \mathrm{~K}$.

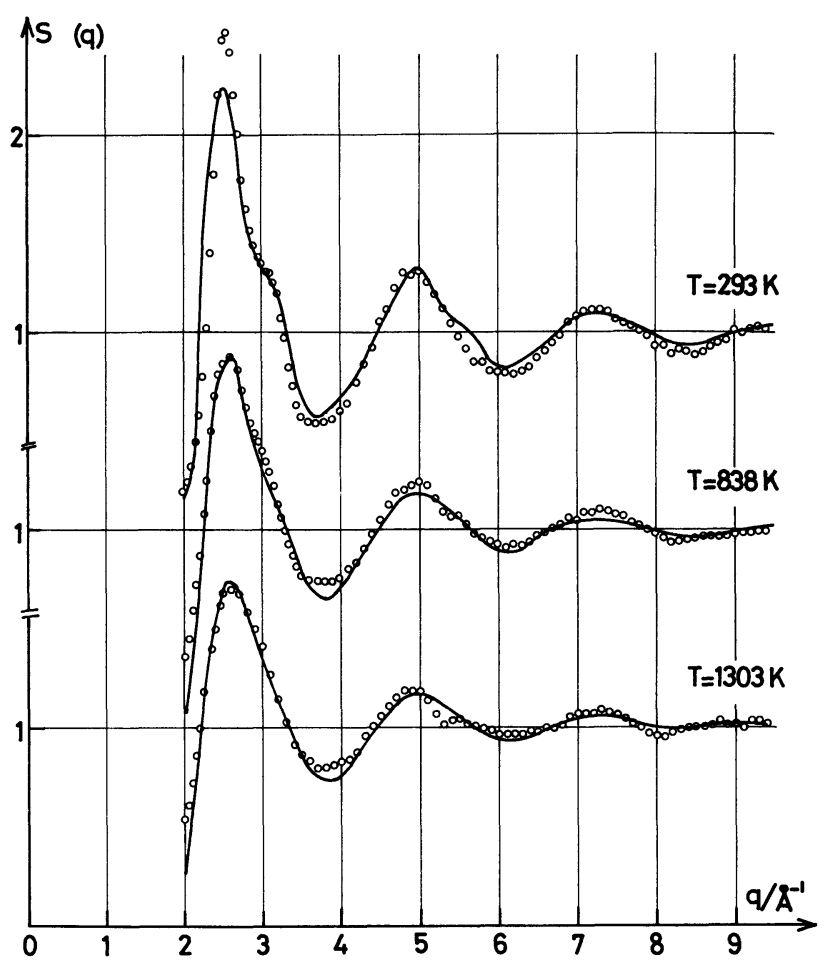

FIG. 5. - Comparison between measured (given by the dotted line) and simulated (given by the full line) structure factors at 293, 838 and $1303 \mathrm{~K}$.

All the calculated structure factors $S(q)$ were obtained from a set of mean neighbour distances identical to those of $\beta$ monoclinic gallium. In order to take into account the minima value of the experimental radial distribution function $g(r)$ at about $4 \AA$, the corresponding distribution of distances have been smoothed (the width of the corresponding gaussian distributions reached 1.5 to 2 between 3.8 and $4.3 \AA$ instead of 0.5 for other distances).

We have obtained in this way the simulated structure factor for liquid gallium at room temperature, plotted as a full line on figure $5(293 \mathrm{~K})$.

The effect of increasing temperature is then introduced by assuming a broadening of the gaussian peaks and a reduction of the correlation length. In order to give a more quantitative meaning to this correlation length, we define it as the distance from which the relative variation of density in the radial distribution function becomes smaller than a limit value arbitrary chosen to be 0.01 .

The structure factors for 838 and $1303 \mathrm{~K}$ were obtained respectively with 1.2 and 1.4 broadening of the room temperature distribution of distances.

The correlation lengths were approximately 11,10 and $9 \AA$ for 293,838 and $1303 \mathrm{~K}$ respectively. So that the values of $S(k)$ for small $k$ (less than $2 \AA^{-1}$ ) are not significant. It should be noticed that the agreement between the measured and calculated structure factors is of the same order of magnitude as the statistical error which could be associated with our measurements (about $5 \%$ ).

We therefore obtained a good representation of the structure factors as well as the positions and the intensities of all the peaks including the shoulder in the high-angle side of the first peak at 293 and $838 \mathrm{~K}$.

5. Discussion. - The anomalous behaviour of the experimental structure factor of liquid gallium (e.g. the pronounced shoulder of the first peak which slowly vanishes with increasing temperature) suggested to us that the local order cannot be explained by geometrical effects only. Thus it seemed impossible to describe local order in the whole range of wavevector $q$, in terms of a hard sphere model or a model of more or less softened spheres [27]. Therefore in order to take into account a possible local anisotropy, we have used a quasicrystalline model in which the atomic neighbourhood characteristics of the gallium bonds, will be already present. Among the various forms of crystalline gallium that we have used, the $\beta$ monoclinic phase provides us with the best fit for the structure factor at room temperature. Moreover, by introducing additional disorder when the temperature increases we showed that the same model was still convenient provided that the gaussian distributions are softened and that the correlation lengths are reduced.

These results are consistent with those of our structural study showing a modification of the coordination number which can be explained, essentially by the variation of the bulk density without noticeable modification of the coordination number.

6. Conclusion. - In this paper we present a determination of the interference functions of liquid gallium by means of neutron scattering at temperatures of 293,838 and $1303 \mathrm{~K}$. We have calculated by means of a Fourier transform the pair correlation function $g(r)$ and the corresponding number of nearest neighbours. These results are fairly consistent with various previous data. The continuous variation of the structure factor $S(q)$ and the pair correlation function $g(r)$ with increasing temperature suggests a smooth evolution rather than a drastic modification of the structure.

We have therefore obtained a good representation of the structure factor throughout the whole range of temperature from a quasi-crystalline model based on $\beta$ monoclinic gallium. Thus we believe that the local order of liquid gallium is very closely related to the structure of this crystalline form.

Moreover it should be emphasized that the supercooled gallium crystallizes more often than not in the $\beta$ monoclinic form at low temperature. 


\section{References}

[1] DutchaK, Ya. I., MikolaichoK, O. G. and Klim, M. M., Fiz. Met. Metalloved. 14 (1962) 548.

[2] Bizid, A., Bosio, L., Curien, H., Defrain, A. and Dupont, M., Phys. Status Solidi A 23 (1974) 135.

[3] Rodriguez, S. E. and Pings, C. J., J. Chem. Phys. 42 (1965) 2436.

[4] Ascarelli, P., Phys. Rev. 143 (1966) 36.

[5] Bizid, A., Bosio, L. and Cortes, R., J. Chim. Phys. 74 (1977) 7-8.

[6] WASEDA, Y. (1975) (private communication).

[7] Narten, A. H., J. Chem. Phys. 56 (1972) 1185.

[8] Lashko, A. S. and Poltantsen, Yu. G., Ukr. Fiz. Zh. 13 (1968) 1575.

[9] Wagner, C. N. J., 3rd Inter. Conf. Liq. Metals. Bristol (1976).

[10] Suzuki, K., Misawa, M. and Fukushima. Y., Trans. Japan Inst. Met. 16 (1975) 297.

[11] Zei, M. S. and StefFen, B., J. Phys. ( $/ \mathrm{c} m .80$ (1977) 919.

[12] Tourand, G., Thesis, Paris (1971) A.O. CNRS.

[13] Tourand, G. and Breull, M., Colloque International du CNRS (France) 205 (1971) 199.

[14] Tourand, G. and Breuil, M., J. Physique 32 (1971) 813.

[15] Schult L, L. G., J. Opt. Soc. Am. 47 (1957) 64.
[16] Paalman, H. H. and Pings, C. J., J. Appl. Phys. 33 (1962) 2635.

[17] Bacon, G. E., Acta Crystallogr. A 28 (1972) 357.

[18] Neutron Cross Section, BNL 325 (Brookhaven' National'Laboratory) 2nd edition (1958).

[19] Richards, T. W. and Boyer, S., J. Am. Chem. Soc. 43 (1921) 274.

[20] Hoather, W. H., Proc. Phys. Soc. 48 (1936) 699.

[21] Köster, H., Hensel, F. and Franck, E. U., Ber. Bunsenges., Phys. Chem. 74 (1970) 43.

[22] Spells, K. E., Proc. Phys. Soc. 48 (1936) 299.

[23] Blech, I. A. and Averbach, B. L., Phys. Rev. A 137 (1965) 1113.

[24] Antonini, M. and Corchia, M., Nuovo Cimento B 10 (1972) 117.

[25] Placzek, G., Phys. Rev. 86 (1952) 377.

[26] Yarnell, J. L., Katz, M. J., Wenzel, R. G. and KöeniG, S. H., Phys. Rev. A 7 (1973) 2130.

[27] Bizid, A., Thesis, Paris VI (1977) A.O. CNRS.

[28] Bellissent, R. and Tourand, G., J. Physique 37 (1976) 1423 and Int. Conf. on Liq. and amorphous semi-conductors, Leningrad (1975) 18/24 nov., proceedings, p. 160.

[29] Bellissent, R. and Tourand, G. (1977), Int. Conf. Liq. amorphous semi-conductors, Edinburgh, June 1977. 